\title{
Management of Severe Acute Malnutrition in a Senegalese Paediatric Hospital
}

\section{Ndiogou Seck ${ }^{*}$, Idrissa Basse ${ }^{2}$, Djibril Boiro ${ }^{3}$, Younoussa Keïta ${ }^{4}$, Lamine Thiam ${ }^{5}$, Aliou Abdoulaye Ndongo ${ }^{4}$, Ndéye Rama Diagne-Gueye ${ }^{2}$}

\author{
${ }^{1}$ Service de péDiatrie, Centre Hospitalier Régional de Saint-Louis, Saint-Louis, Sénégal \\ ${ }^{2}$ Hôpital pour Enfants de Diamniadio, Bargny, Sénégal \\ ${ }^{3}$ Service de péDiatrie, Centre Hospitalier Abass Ndao, Dakar, Sénégal \\ ${ }^{4}$ Service de péDiatrie Hôpital Aristide Ledantec, Dakar, Sénégal \\ ${ }^{5}$ Service de PéDiatrie, Hôpital de la Paix, Boucoutte, Ziguinchor, Sénégal \\ Email: ^ndiogou.seck@ugb.edu.sn
}

How to cite this paper: Seck, N., Basse, I., Boiro, D., Keïta, Y., Thiam, L., Ndongo, A.A. and Diagne-Gueye, N.R. (2021) Management of Severe Acute Malnutrition in a Senegalese Paediatric Hospital. Open Journal of Pediatrics, 11, 198-207.

https://doi.org/10.4236/ojped.2021.112019

Received: March 16, 2021

Accepted: May 25, 2021

Published: May 28, 2021

Copyright $\odot 2021$ by author(s) and Scientific Research Publishing Inc. This work is licensed under the Creative Commons Attribution International License (CC BY 4.0).

http://creativecommons.org/licenses/by/4.0/

(c)

\begin{abstract}
Malnutrition is a global health problem. It is very common in developing countries where it contributes to an increase in morbidity and mortality, especially among children under five years of age. The main objective of this study was to describe the management of severe acute malnutrition (SAM) in children six months to five years of age hospitalized at Diamniadio Children's Hospital (DCH). This was an epidemiological, retrospective, descriptive and cross-sectional study of children aged six to 59 months hospitalized at DCH for SAM. The study took place over a 12-month period (from January 1, 2018 to December 31, 2018). During the study period, 67 children were admitted for SAM, representing a hospital prevalence of $8.4 \%$. The majority $(88 \%)$ children were less than 24 months old. Reasons for consultations were dominated by diarrhea (57.5\%) vomiting (38.8\%). Complications related to SAM were mainly: anaemia (74.6\%), infections (85\%) and severe acute dehydration (40.3\%). Factors associated with SAM were young age (infants under 24 months of age), poverty, the first four children of a sibling, poor behaviour of food diversification. The average length of hospitalization was 12 days. The nutritional recovery rate was $73.1 \%$ and lethality was $3 \%$. Conclusion: The prevention of malnutrition must involve the fight against poverty, an optimal and well-diversified diet, monitoring the nutritional status of children up to five years of age.
\end{abstract}

\section{Keywords}

Severe Acute Malnutrition, Children, Complications, Risk Factors, Lethality 


\section{Introduction}

Malnutrition is a major health problem worldwide, particularly in developing countries where it contributes to an increase in morbidity and mortality.

It particularly affects children from six months to five years of age and affects their intellectual development and their ability to perform in adulthood.

Globally, nearly 165 million children under five are stunted, 52 million are acutely malnourished, including 17 million who are severely malnourished [1]. Malnutrition is said to be responsible for three million deaths worldwide each year, much of which is recorded in Africa and Southeast Asia [2].

In Senegal, according to the 2018 Demographic and Continuous Health Survey: $18.8 \%$ of children under five are stunted, $15.1 \%$ are underweight and $7.8 \%$ suffer from global acute malnutrition [3].

The management of malnutrition in Senegal is well codified. Uncomplicated forms are taken care of in recovery and nutritional education units (UREN) installed in health centers; as for the complicated severe forms, they come under hospitals in the centers of recovery and nutritional education (CREN).

The overall objective of this study was to describe the management of severe acute malnutrition (SAM) in children six months to five years of age hospitalized at Diamniadio Children's Hospital (DCH).

The secondary objectives were to:

- Determine the prevalence of SAM in children six months to five years of age at the $\mathrm{DCH}$.

- Identify the various complications related to SAM in children aged six months to five years admitted to the DCH.

- Identify the different risk factors for the occurrence of SAM in children aged six months to five years admitted to the DCH.

- Determine SAM-related lethality in children six months to five years of age admitted to the Diamniadio Children's Hospital.

\section{Patients and Method}

\subsection{Study Framework}

The study was carried out at the DCH which is a level III public health establishment. It is one of the benchmark pediatric centers in the regions of Dakar and Thiès; Diamniadio being a crossroads city. It is a University Hospital with a capacity of 140 beds. The medical staff is entirely made up of pediatricians. During 2018, the hospital had recorded almost 35,000 consultations.

\subsection{Type of Study}

This was an epidemiological, retrospective, descriptive and cross-sectional study of children aged six to 59 months hospitalized at DCH for SAM. The study took place over a 12-month period (from January 1, 2018 to December 31, 2018). 


\subsection{Inclusion Criteria}

The survey covered children aged six to 59 months admitted to the DCH hospitalization unit for SAM during the study period.

The diagnosis of SAM was based on the following criteria:

- A weight-for-height ratio of less than -3 standard deviations $(<-3$ DS) according to the WHO growth charts; and/or

- A brachial perimeter less than $115 \mathrm{~mm}$; and/or

- The presence of nutritional-type edema in the lower and/or upper limbs.

\subsection{Criteria for Non-Inclusion}

Infants under six months of age and children over five years of age with SAM were not included in this study.

\subsection{Data Collection and Analysis}

Data were collected from registers (hospitalization and nutritional monitoring) and medical records of hospitalization. A pre-established survey sheet made it possible to collect the various data. These were: socio-demographic data (age of the child, siblings, mode of breastfeeding, management of diversification, level of education of the mother, etc.), clinical parameters (anthropometric and clinical data), parameters biological (glycemia, hemoglobin level, CRP, protidemia, retroviral serology, etc.), therapeutic and evolutionary parameters.

The data from the survey sheets were entered into Microsoft Excel before being analyzed by the Epi info 7 software.

The results were refined and compared to statistical tests including the Khi 2 continence test. A P value less than 0.05 was considered significant

\section{Results}

During the study period, 794 children aged six months to five years were hospitalized; among them, 67 were admitted for SAM, i.e., a hospital prevalence of $8.4 \%$.

There were almost as many boys as girls ( 35 and 32 respectively), a sex ratio of 1.09 .

The average age of malnourished children was 16.7 months. The distribution by age group showed a majority of children (59\% or $88 \%$ ) aged six to 24 months (Figure 1).

The rank occupied by the child in the siblings has been studied; SAM was more frequent in the first four siblings with prevalence of $23.9 \%$ in the first child, $14.9 \%$ in the second, $17.9 \%$ in the third and $17.9 \%$ in the fourth.

From the fifth child, there was a significant decline in this prevalence (Figure 2).

The young age of the mother was not associated with an increase in the prevalence of SAM, in fact, only $6 \%$ of malnourished children came from mothers under the age of 18 .

The frequency of SAM was lower in children of multiparous mothers. 


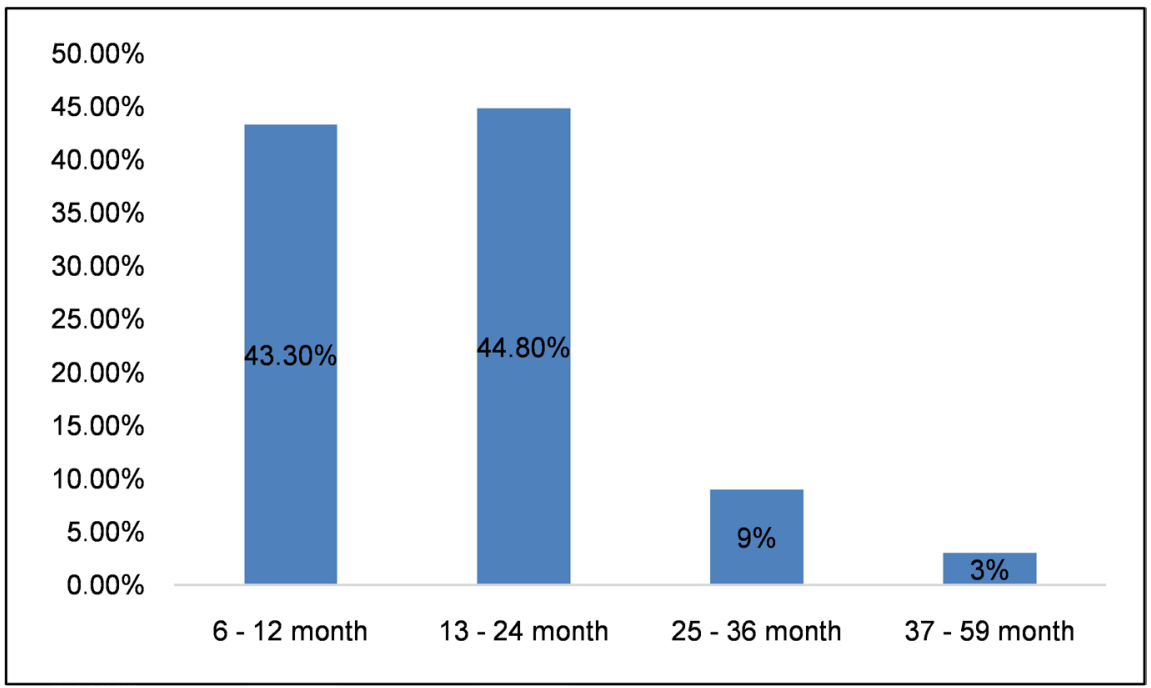

Figure 1. Distribution by age group.

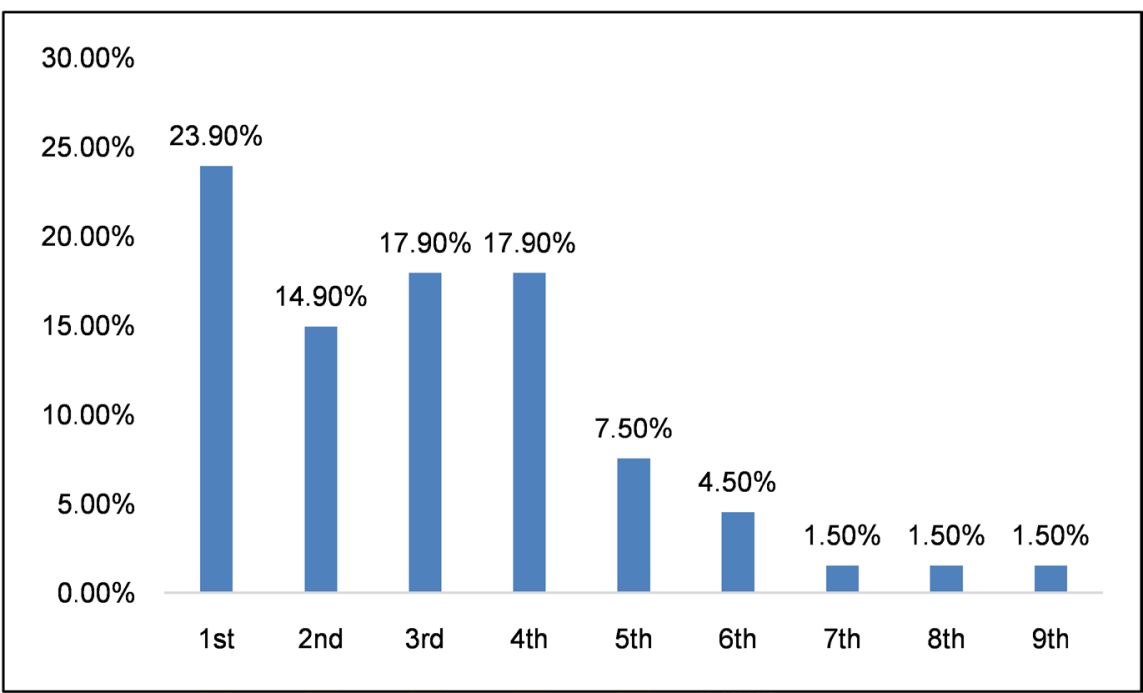

Figure 2. Distribution by the rank occupied by the child in the siblings.

Two thirds of the children (44 out of 67 ) or $65.6 \%$ came from a poor family with a low socio-economic level.

Exclusive breastfeeding, recommended by national health guidelines, was observed in 50 children (74.6\%). Fifteen children (22.4\%) had benefited from early food diversification before the sixth month of life and in almost $40 \%$ the age at which diversification began (six months) was respected. Six children out of 50 (12\%) who were on exclusive breastfeeding were weaned early before 18 months.

The nutritional value and daily calorie intake of complementary foods have not been evaluated.

Clinically, the reasons for consultation were dominated by digestive disorders including diarrhea and vomiting observed in $57.5 \%$ and $38.8 \%$ of children respectively. Twenty-six patients (38.8\%) were being consulted for a febrile condition (Figure 3). 


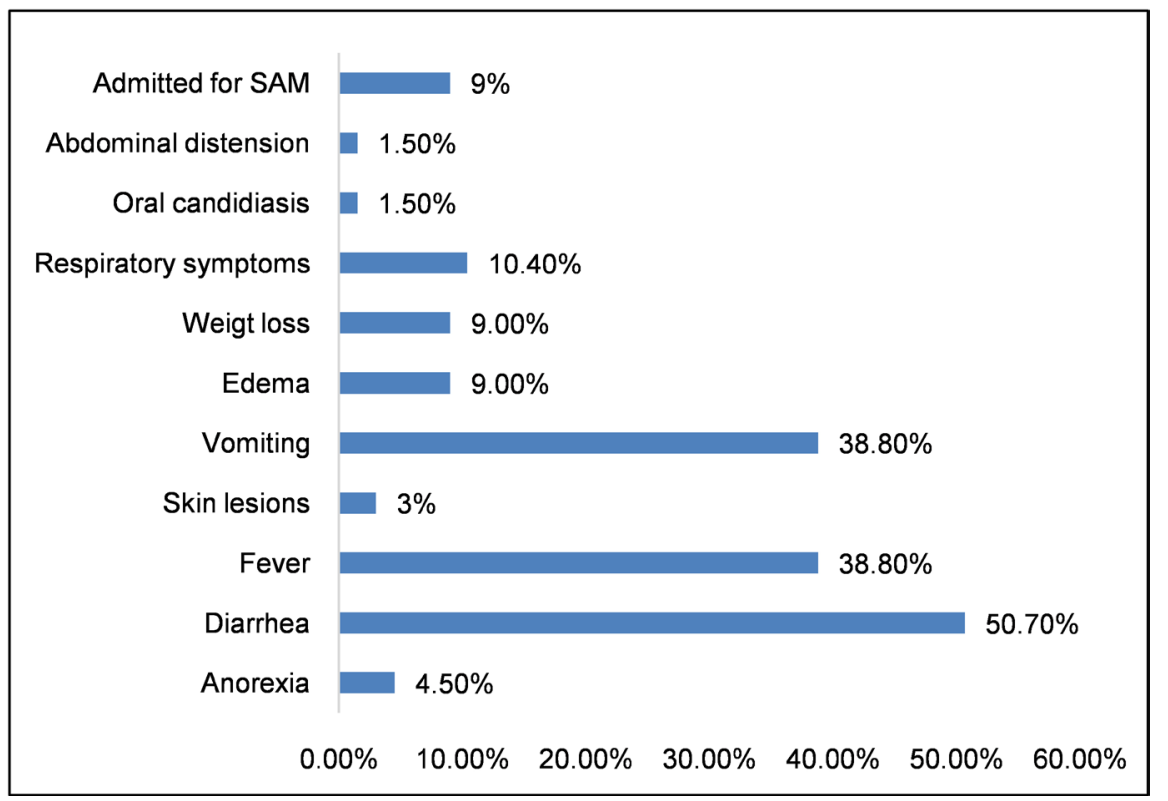

Figure 3. Distribution by the reasons for consultation.

Referring to the diagnostic criteria, SAM was retained in 61 children (91\%) on the basis of the criteria (weight-for-height ratio of the WHO curves less than -3 DS); for the remaining six children, the diagnosis was confirmed by the presence of edema of variable nutritional type associated with a lower arm circumference of $115 \mathrm{~mm}$.

Biologically, a hemogram and a CRP assay were performed on almost all of our patients. Anemia with an average hemoglobin level of $9.4 \mathrm{~g} / \mathrm{dl}$ was observed in $50(74.6 \%)$ patients. CRP was positive (greater than $6 \mathrm{mg} / \mathrm{dl}$ ) in $80 \%$ of the children. Other biological analyzes were carried out depending on the availability and the means of the patient. A hypo protidemia with an average protidemia at $49.36 \mathrm{~g} / \mathrm{l}$ was found in 16 out of 22 children tested, a hypo natremia in 27 children and a hypo kalaemia in 18 out of 52 children who benefited from a blood ionogram. Two children had positive HIV serology out of 28 children tested.

Complications related to SAM were dominated by infections (57 children or $85 \%$ ), anemia (50 children or $74.6 \%$ ) and severe dehydration (27 children or $40.3 \%$ ). Only one case of hypoglycemia was noted (Figure 4).

The locations of these infections were presented in (Figure 5).

A predominance of acute respiratory infections (57.8\%) and acute gastroenteritis (AGE) (42.1\%) was observed. Bacteriological analysis had confirmed: seven cases of bacterial AGE with Escherichia coli, four cases of pleuro-pulmonary staphylococcal disease, two cases of sepsis with Streptococcus pneumoniae and one case of urinary infection with Klebsiella pneumoniae.

All of our patients had received nutritional care with F75 therapeutic milks in the first phase of treatment, then F100 and ready-to-use therapeutic foods (RUTF) such as "plumpy nut" in the second phase. Therapeutic education sessions were regularly organized for parents. 


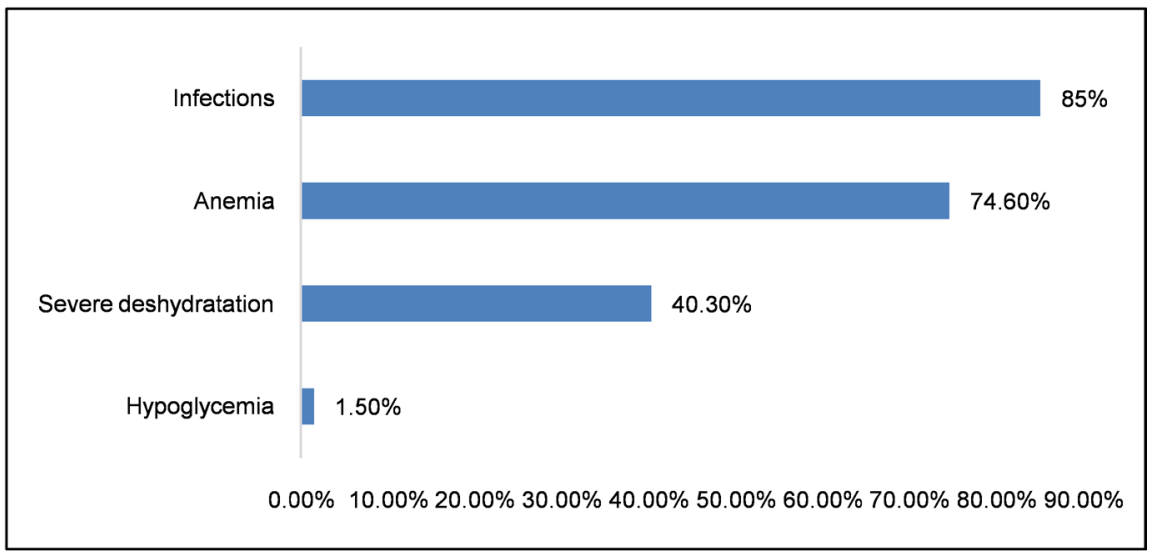

Figure 4. Major complications related to SAM.

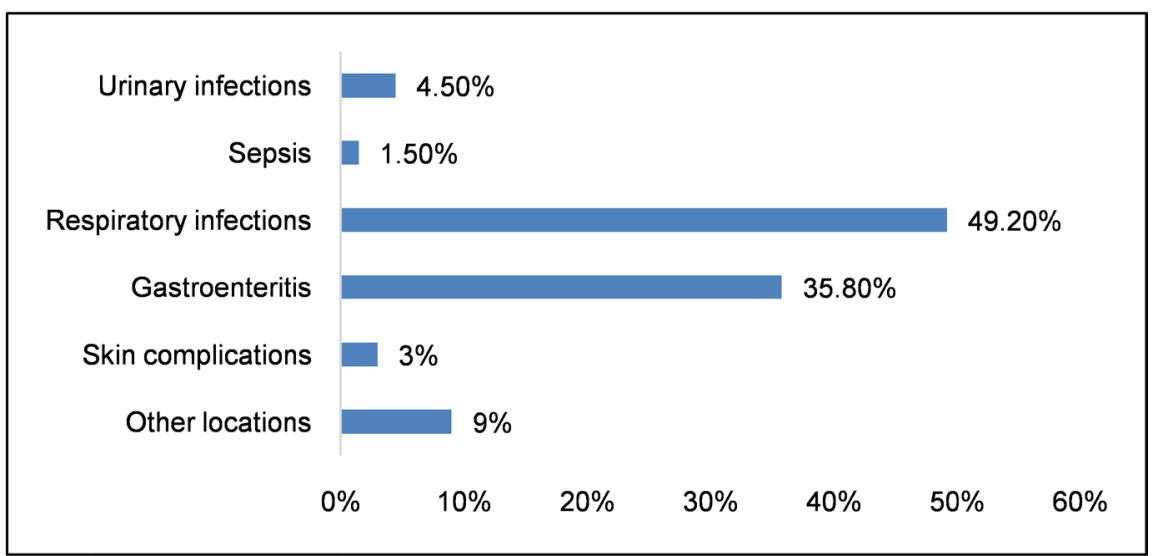

Figure 5. Locations of infectious complications.

The average length of hospital stay was 12 days with a maximum of 36 days. The lethality was $3 \%$. Forty-nine children were declared cured going from a state of SAM to a normal nutritional state or a state of moderate acute malnutrition (MAM) that is a nutritional recovery rate of $73.1 \%$; two children were lost to follow-up.

\section{Discussion}

The hospital prevalence of SAM in our study is clearly above the national prevalence of $2 \%$ found in the 2017 Demographic and Continuous Health Survey; however, this rate remains low compared to the $22.9 \%$ rate found in the pediatrics department of Aristide Le Dantec Hospital (HALD) in 2015 [4]. SAM is a common pathology in pediatric structures, the HALD pediatrics service with the Albert Royer children's Hospital (ARCH) constitute the main pediatric reference structures in the Dakar region, which explains the high prevalence of SAM in these structures.

Malnutrition is common in developing countries, especially those in sub-Saharan Africa and Southeast Asia. In Ethiopia, in rural areas the prevalence of global malnutrition is $48.5 \%$ [5]; Regarding SAM, its prevalence is $7.5 \%$ in India; $8.8 \%$ 
in Nigeria in 2013; 3.8\% in Egypt in 2014 and 1.4\% in Uganda in 2016 [6] [7].

The average age of malnourished children was 16.7 months and almost half (43.3\%) were six to 12 months old. The majority of SAM occurred during the first two years of life ( $88 \%$ of children). Similar results were found in two other studies in Senegal: in the Bambey health district, in 2015, the average age of malnourished children was 16.3 months [8] and at the Institute of Social Pediatrics (ISP) in Dakar, the 2007 study showed that almost $44 \%$ of malnourished children were less than 12 months old [9]. In Niger, a study carried out in six health districts found a predominance of malnutrition in children aged six to 29 months [10].

These results show that infants are at higher risk. This vulnerability could be explained by poverty, illiteracy of mothers, poor food diversification, the frequency of infections such as diarrhea and malaria.

In our study, two thirds of the children came from poor households.

The rate of exclusive breastfeeding was almost $75 \%$, the recommended period for weaning was respected by $88 \%$ of mothers. However, one in four children was diversified early.

Besides poverty, diet and infection are risk factors for developing malnutrition in infants. Poor dietary diversification resulting in a deficit in calories, nutrients, vitamins and mineral salts triples the risk of developing malnutrition in children under five years of age [11]. There is also a synergistic relationship between the frequency of infections and malnutrition with a relative risk of 2.6 [11]. Repeated infections may be the cause or consequence of an immune deficiency resulting from malnutrition.

The risk of developing malnutrition is high in the first four children of siblings. This factor was found in our study, nearly $75 \%$ of the patients occupied the first four rows of siblings. Other factors such as the young age of the mother and illiteracy have also been mentioned [7].

Few patients consult for underweight or isolated wasting. It is often the appearance of one or more symptoms that lead parents to consult health facilities. In our survey, the reasons for consultation were dominated by the diarrhea observed in more than half of the children (57.5\%); it can be the cause or a consequence of malnutrition. It is followed by vomiting $(38.8 \%)$, fever $(38.8 \%)$ and lesser signs of breathing (10.4\%). These symptoms have been found in numerous studies as the main reasons for admission [12] [13] [14].

The diagnosis of SAM is based on anthropometric criteria (weight, height...) and the presence of edema of the nutritional type; paraclinical exploration is only carried out in search of complications. The protidemia was only carried out in a few children (22 out of 67 ), it was reduced in the $16(72.7 \%)$. The presence of a hypopridemia favors kwashiorkor malnutrition.

The severity of SAM is linked to the occurrence of complications, some of which are life-threatening in the absence of urgent and effective treatment. These complications can be hypothermia, hypoglycemia, severe dehydration, shock, 
severe anemia, infection, anorexia, loss of appetite [7].

In our study the main complications were infectious complications (85\%) dominated by acute respiratory infections (57.8\%) and acute gastroenteritis $(42.1 \%)$, anemia (75.6\%) and severe dehydration (40.3\%). Only one case of hypoglycemia was noted.

Malnutrition is often a risk area for acute respiratory infections. The rate observed in our study is significantly higher than the data in the literature: $9.6 \%$ in the FAHE study in HALD [15], 20\% in the IPS in Dakar [9] and 24.4\% in a study carried out in Mali in 2009 [16].

Anemia is frequently associated with malnutrition. In the majority of studies, more than half of malnourished children have anemia; $73.8 \%$ in the Fotso study at ARCH [17], 69\% at the ISP in da Dakar [9], 69.9\% at HALD [15], 76.5\% in Morocco and 60\% in Cameroon [18] [19].

This anemia can be secondary to an iron and/or folate deficiency, to repeated parasitic infestations, to inflammation... most often it is multi-factorial.

Severe dehydration was the third complication encountered; it was the main complication (90\% of malnourished children) in Fahe's work at HALD [15]. It can be difficult to recognize in malnourished children. Its management is urgent and responds to well-defined protocols.

According to the World Health Organization (WHO), the correct management of SAM in developing countries should make it possible to reduce mortality to less than $5 \%$, to obtain a minimum cure rate of $75 \%$, a duration of hospitalization of less than 30 days with an average daily weight gain of $8 \mathrm{~g} / \mathrm{Kg} / \mathrm{day}$ [20].

In our study the lethality was $3 \%$, the cure rate of $73.1 \%$ was below the $\mathrm{WHO}$ targets, the average length of stay was 12 days, and the average daily weight gain was $8.9 \mathrm{~g} / \mathrm{Kg} / \mathrm{d}$. This lethality was lower than that observed by Fahe (7\%) and Fotso (11.3\%) [15] [17]; it is slightly above the $2.1 \%$ rate observed in Ethiopia [20].

The limits of our study were: its retrospective nature, certain parameters were not taken into account; the absence of a dietary and nutritional survey to assess the daily caloric intake of children undergoing diversification or receiving complementary food in order to better assess the recommended nutritional intake.

\section{Conclusions}

SAM is responsible for increased morbidity and mortality in children under the age of five.

In our study, the prevalence was low. Complications were dominated by respiratory infections and anemia; the lethality was $3 \%$. Several factors could explain the occurrence of SAM: infants under 24 months, poverty, the first children of a sibling, poor food diversification...

Efforts must be made in its prevention which must be focused on:

- Improving the standard of living of the populations;

- The fight against poverty; 
- Promotion of exclusive breastfeeding up to six months;

- Education of mothers on the principles of food diversification and promotion of local foods;

- Vaccination and infection control;

- Monitoring the nutritional status of children from birth to 5 years of age.

\section{Conflicts of Interest}

The authors declare no conflicts of interest regarding the publication of this paper.

\section{References}

[1] Black, R.E., Victora, C.G., Walker, S.P., et al. (2013) Maternal and Child Undernutrition and Overweight in Low-Income and Middle-Income Countries. The Lancet, 382, 427-451. https://doi.org/10.1016/S0140-6736(13)60937-X

[2] De Onis, M., Brown, D., Blossner, M. and Borghi, E. (2012) Levels and Trends in Child Malnutrition. UNICEF-WHO-The World Bank Joint Child Malnutrition Estimates. http://www.who.int/nutgrowthdb/jme_unicef_who_wb.pdf

[3] Agence Nationale de la Statistique et de la Démographie (ANSD) du Sénégal. Rapport provisoire Enquête Démographique et de Santé Continue de 2018. https://www.rhsupplies.org/uploads/tx_rhscpublications/Sénégal_-_2018_01.pdf

[4] Sylla, A., Gueye, M., Keita, Y., Seck, N., Seck, A., Mbow, F., Ndiaye, O., Diouf, S. and Sall, M.G. (2015) Déshydratation et malnutrition: Deux facteurs de risque de décès indépendants chez l'enfant sénégalais hospitalisé. Archives de Pédiatrie, 22, 235-240. https://doi.org/10.1016/j.arcped.2014.11.024

[5] Endris, N., Asefa, H. and Dube, L. (2017) Prevalence of Malnutrition and Associated Factors among Children in Rural Ethiopia. BioMed Research International, 2017, Article ID: 6587853. https://doi.org/10.1155/2017/6587853

[6] Awasthia, S., Vermaa, T., Sanghvib, T. and Frongilloc, E.A. (2019) Path to Severe Acute Malnutrition in Children below 2 Years of Age: Findings of Qualitative Research in Uttar Pradesh, North India. Clinical Epidemiology Global Health, 7, 246-252. https://doi.org/10.1016/j.cegh.2018.11.001

[7] Fagbamigbe, A.F., Kandala, N.B. and Uthman, O. (2020) Severe Acute Malnutrition among Under-Five Children in Low- and Middle-Income Countries: A Hierarchical Analysis of Associated Risk Factors. https://ssrn.com/abstract=3466988

[8] Sow, N. (2015) Etude des déterminants de la malnutrition aiguë chez les enfants âgés de 6 à 59 mois dans le district sanitaire de Bambey (Sénégal). Thèse Med Dakar: UCAD.

[9] Diallo, A. (2007) La malnutrition protéino-énergétique chez l'enfant au CREN de l'IPS de Pikine: Aspects épidémiologique, cliniques et thérapeutiques. Thèse Med. Dakar: UCAD.

[10] Quelin, G., Peloul, B., Amadou, B., et al. (1991) Facteurs de risqué de la malnutrition chez les enfants de 0 à 59 mois dans deux arrondissements du Niger. Medecine Tropicale, 51, 335-342

[11] Mayangsaria, R. and Syahrulb, S. (2020) Food Intake and Infectious Diseases among Malnutrition Toddlers in Rural Area of Muna Regency. Enfermería Clínica, 30, 341-344. https://doi.org/10.1016/j.enfcli.2019.10.024

[12] Camara, B., Diouf, S. and Faye, P.M. (2005) Morbi-mortalité en milieu hospitalier 
pédiatrique Dakarois (Sénégal). Archives de Pédiatrie, 12, 1777-1778. https://doi.org/10.1016/j.arcped.2005.09.022

[13] Koffi, K.S., Guédéhoussou, T., Djadou, K.E., et al. (2010) Morbi-mortalité des enfants de 0 à 15 ans hospitalisés en pédiatrie à l'hôpital de Bé (Togo) en 2005. Archives de Pédiatrie, 17, 1108-1110. https://doi.org/10.1016/j.arcped.2010.03.015

[14] Mc Carthy, J.E. and Evans-Gilbert, T. (2009) Descriptive Epidemiology of Mortality and Morbidity of Health-Indicator Diseases in Hospitalized Children from Westem Jamaica. American Journal of Tropical Medicine and Hygiene, 80, 596-600. https://doi.org/10.4269/ajtmh.2009.80.596

[15] Fahe, C. (2015) Malnutrition chez les enfants âgés de 0 5ans hospitalisés à l'hôpital Aristide le Dantec en 2012 aspects épidémiologiques, cliniques et évolutif. Thèse Med. Dakar: UCAD.

[16] Sangaré, B.B.O. (2009) Evaluation de la prise en charge de la malnutrition aiguë sévère dans le service de pédiatrie de l'hôpital de GAO. Thèse Med: Université de Bamako.

[17] Fotso, M. (2013) Malnutrition chez les enfants âgés de 0 à 5 ans hospitalisés à l'hôpital Albert Royer, aspects épidémiologiques et évolution des paramètres anthropométriques. Thèse Med Dakar: UCAD.

[18] Ministère de la santé publique du Cameroun. Enquête Démographique et de Santé et à Indicateur Multiples EDS-MICS. Douala 2011.

[19] Hioui, M.E., Aboussakh, Y., Ahami, A., et al. (2009) Contribution à l'étude de la prévalence de l'anémie chez les enfants d'âge préscolaire de la région de Kenitra Maroc. Anthropology, 1, 1-5.

[20] Abatea, H.K., Kidaneb, S.Z., Feyessab, Y.M. and Gebrehawariat, E.G. (2019) Mortality in Children with Severe Acute Malnutrition. Clinical Nutrition ESPEN, 33 , 98-104. https://doi.org/10.1016/j.clnesp.2019.07.001 